\title{
DIGITAL PLATFORMS AS MEDIATOR OF PUBLIC COMMUNICATION
}

\author{
Leonid Smorgunov and Olga Ignatjeva \\ Saint Petersburg State University, 7-9 Universitetskaya Emb., St Petersburg 199034, Russia
}

\begin{abstract}
Research into the impact of information and communication technologies (ICT) on the field of public communication has a big importance nowadays. This article is aimed at studying the influence of lay epistemics on the formation of judgments in the course of communication on digital platforms between government officials and the citizens. To study the functioning of the process of forming judgments on digital platforms of communication between the authorities and citizens, we have worked out a new methodology of discourse analysis based on theory of lay epistemics. We stem on communication on the 'Our St. Petersburg' platform. The descriptive and regression analysis of judgements with the aid of the programming language $\mathrm{R}$ allows us to reveal that this platform is belonged to informative type of communication based on the behavioral principle of "stimulus-response". It was also found that the criteria of the parametric model have a different effect on the formation of a certain type of judgment in the framework of public communication on digital platforms.
\end{abstract}

\section{KEYWORDS}

Digital Platforms, Public Communication, Lay Epistemics, Judgment, Epistemic Authority

\section{INTRODUCTION}

Studies of the role of public communication and digital technologies in modern politics form a significant layer of literature in political science, which is actively replenished in various directions. The theory of communication studies is being developed in Russia and the processes of influence on political communication of new media are being investigated. A number of works reveal various aspects of the growing influence of new ICTs on politics and communication processes (see: Akopov, 2015; Bykov, 2013; Volodenkov, 2018, etc.). Some researchers directly argue that digital platforms are not politically neutral, and their architecture directly affects the results of political campaigns (Bossetta, 2018; Lukito, 2020). D. Kreis and S. McGregor provide evidence that during the 2016 US presidential election. IT giants were involved in election campaigns not on commercial but on political grounds (Kreiss., McGregor, 2018). Modern public communication is no longer limited to the traditional exchange of political information between people, it is moderated by very sophisticated methods in digital platforms, which opens up almost limitless possibilities for covert manipulation of public consciousness not only in authoritarian but also democratic countries (Computational ..., 2019; Howard, 2010; Morozov, 2011). The aim of the study is to examine the impact of digital platforms on the production of communication judgments. The city platform "Our St. Petersburg" was taken as an empirical object of our research. The study was conducted in 2020.

\section{DISCOURSE ANALYSIS OF JUDGMENTS ON DIGITAL PLATFORMS}

Digital platforms of communication between citizens and authorities are becoming part of the implementation of public governance in the modern world. They can be differentiated into four types: platforms for citizens' appeal, portals for urban (regional) problems, portals for assessing initiatives, portals / platforms for public participation. These portals (platforms) have different architectures and, accordingly, a set of affordances, which in a certain way affect the nature of communication and the formation of the prevailing type of judgments. In the process of research, the judgments formed on the platforms were classified into three types: information, general deliberative, and cognitive deliberative. Information judgments are judgments that express 
information about any observable facts and can contain logical connectives (what, if, because, therefore, therefore). The other two types of judgments are deliberative, and to identify such judgments it is necessary to focus on the discourses that may contain them. General deliberative judgments - judgments containing text, open for further discussion and finding a common position. Cognitive deliberative judgments are judgments containing text, aimed at finding additional knowledge in the process of discussion.

To analyze communication processes on the 'Our St. Petersburg' platform, a toolkit was developed taking into account six criteria that influence the formation of human judgments, based on the concept of lay epistemics and the parametric model of judgments by Ari Kruglanski (Kruglanski et al., 2010. P. 939-950; Kruglanski et al., 2007. P. 255-303), which has undergone a certain modification. A scale of discussion intensity from 0 to 3 and the three above-mentioned types of judgments were introduced into the toolkit.

The first criterion - informational relevance (criterion A) - characterizes the importance of the topic for the communicating parties, which increases from information to cognitive deliberative type of judgments. The second criterion - the task demands (criterion B) - determines the level of complexity of the derivation of the syllogism based on the general and particular premise. In general, deliberative judgment, there is a syllogism with a probabilistic or incomplete conclusion. And only in the case of cognitive deliberative judgments is there maximum intensity when a syllogism with a completed and affirmative conclusion is present in the judgment. Cognitive resources (criterion $C$ ) is the third criterion and characterize the degree of concentration of attention as the intensity of discussion of a topic / problem. The degree of intensity of this criterion increases with the movement from information to cognitive deliberative type of judgments. The fourth and fifth criteria refer to the type of motivation (Kruglanski, 1999). Non-directional motivation (criterion D) is determined by the degree of effort spent on determining the subject of discussion, its general nature. Directional motivation (criterion E) determines the level of readiness for a specific / non-specific closure and expresses the desire to continue or stop communication in connection with the certainty of the issue being addressed. Both non-directional and directional motivations gain intensity from information judgements to cognitive deliberative judgements. Epistemic authority (criterion F) is used to legitimize the results of the cognitive process.

Hypothesis. The digital communication platform of the population and regional authorities "Our Petersburg" affects the intensity of the use of the corresponding capacities of ordinary epistemics, which generate chances to produce informational judgments.

To test the hypothesis proposed in the study, a new method of discourse analysis was developed on digital platforms of communication between the population and government authorities. Assessment of judgments based on the modified six criteria and the scale of intensity of lay epistemics made it possible to classify judgments formed within the framework of platform interaction, as well as to determine the effectiveness of a particular criterion.

\section{DESCRIPTIVE AND REGRESSION ANALYSIS OF JUDGMENTS ON THE PLATFORM 'OUR ST. PETERSBURG'}

The sample size of judgments on the 'Our St. Petersburg' platform was 10993 messages, of which $83.9 \%$ were information judgments, $9.1 \%$ were general deliberative judgments, and $7 \%$ were cognitive deliberative judgments. The distribution of mean and standard deviations in judgments by criteria is shown in table. 1 . The mean describes the intensity of epistemic criteria, characteristic, respectively, for information, general deliberative and cognitive deliberative judgments. The standard deviation records the scatter of judgments around the average for the respective types of judgments.

By calculating the averages and the spread of the data around the mean (standard deviation), we estimated how accurately our attribution of judgments to a particular type was obtained. Based on the calculations performed, we came to the conclusion that the standard deviations are not so large for our data. Large values of standard deviations indicate that cognitive judgments require careful assessment. The smaller the discrepancy, the more significant is the criterion for the appropriate judgment.

Thus, information judgments have the smallest average in the region of unity for five criteria (criteria A, B, C, D, E) out of six. They are characterized by a smaller spread of values (standard deviation within $+/-0.5$ ), which means that a more accurate result is presented. Intensity in the region of three units has cognitive deliberative judgments in two cases out of six (criteria A and E), corresponding to the principle of coding by 
seniority (determining the type of judgment based on the degree of deliberation). The standard deviation range for cognitive deliberative judgments is in the range of two units, which indicates the diversity of the form and content of this type of judgments and, possibly, the difficulty of their identification for evaluators. Average in the region of two units have common deliberative judgments,

Data demonstrate the distribution of judgments for each type of criteria, which may indicate the different significance of the criteria in the formation of a particular type of judgment. The distribution of judgments according to criteria for the information type is presented more or less uniformly. This is due to the predominance on this platform of the traditional behavioral model of communication between the authorities and the population according to the 'stimulus-response' type. A slight decrease in the mean value for information judgments is characteristic of the F criterion 'Epistemic authority' (mean value 0.49), which may indicate some distrust of the population in the ability of state authorities to properly resolve their issue.

You can notice some heterogeneity in the distribution of judgments by criteria. So, criteria A 'Informational relevance' and E 'Directional motivation' to the greatest extent affect the formation of a cognitive deliberative judgments. It should be noted that the distribution of types of judgments according to criteria $\mathrm{A}$ and $\mathrm{E}$ is identical for both general deliberative judgments and for cognitive deliberative judgments, that indicates the corresponding regularity and significance of the influence of criteria on the types of judgments.

The situation with respect to criteria B 'Task demands' and C 'Cognitive resources' changes somewhat. They have less influence on the formation of cognitive deliberative judgments and more influence on the formation of general deliberative judgments. This indicates that the judgments posted on the 'Our St. Petersburg' platform are not always complete and correspond to the laws of logic or contribute to the launch of a lengthy discussion. The corresponding trend, but with a lower intensity, demonstrates the distribution of judgments according to the criteria D 'Nondirectional motivation' and F 'Epistemic authority'. This means that the platform 'Our St. Petersburg' either accepts a common theme without raising additional questions, which is typical for general deliberative judgments, or the topic of discussion is taken for granted without specifying it, which is typical for information judgments. According to criterion F 'Epistemic authority', the significance of the criterion falls for all types of judgments, but especially for cognitive deliberative judgment.

A logistic regression model was used to determine the relationship between the dependent variable (the probability of using information judgments) and the corresponding six criteria (predictors). The calculation results are shown in Table 1.

Table 1. Results of constructing logistic regression for information judgments

\begin{tabular}{|l|c|c|c|c|}
\hline Predictors & $\begin{array}{l}\text { Estimation } \\
\text { coefficient }\end{array}$ & $\begin{array}{l}\text { Standard } \\
\text { mistakes }\end{array}$ & Wald Z-tests & $\begin{array}{l}\text { Level } \\
\text { significance }\end{array}$ \\
\hline Intercept & 11.41243 & 0.25710 & 44.390 & $<2 \mathrm{e}-16 * * *$ \\
\hline Criterion A & -1.94983 & 0.06640 & -29.365 & $<2 \mathrm{e}-16 * * *$ \\
\hline Criterion B & -1.70144 & 0.07609 & -22.362 & $<2 \mathrm{e}-16 * * *$ \\
\hline Criterion C & -1.08143 & 0.09003 & -12.012 & $<2 \mathrm{e}-16 * * *$ \\
\hline Criterion D & -0.77266 & 0.06629 & -11.656 & $<2 \mathrm{e}-16 * * *$ \\
\hline Criterion E & -1.73362 & 0.06164 & -28.124 & $<2 \mathrm{e}-16 * * *$ \\
\hline Criterion F & 0.18189 & 0.06873 & 2.646 & $0.00813 * *$ \\
\hline
\end{tabular}

As follows from the data obtained, all six criteria turned out to be statistically significant, and they definitely affect the dependent variable 'Probability of using information judgments'. Based on the data shown in Table 1 , a logistic regression equation was obtained. The resulting logistic regression equation (1) demonstrates the inverse relationship between the predictors (criteria A-E) and the dependent variable (the probability of using information judgments).

\section{logarithm of the odds ratio $=11.41-1.95 *$ criterion $\mathrm{A}-1.7 *$ criterion $\mathrm{B}-1.08 *$ criterion $\mathrm{C}-0.77 *$ criterion $\mathrm{D}-1.74 *$ criterion $\mathbf{E}+\mathbf{0 . 1 8} *$ criterion $\mathbf{F}$

If criterion $\mathrm{A}$ increases by one unit, the odds ratio of using informational judgments increases in 0.14 times, criterion B - in 0.18 times, and criterion E - in 0.18 times, that is, the odds of using informational judgments decreases slightly. When criterion $\mathrm{C}$ increases by one unit, the odds ratio of using informational judgments

${ }^{1}$ Wald's Z-test is an analogue of the Student's t-test for testing parameters in linear regression models. 
increases in 0.34 times, criterion D - in 0.46 times, i.e., the odds of using informational judgments decreases significantly. When criterion $\mathrm{F}$ increases by one unit, the odds ratio of using. informational judgments increase in 1.2 times, i.e. the odds of using informational judgments increase insignificantly.
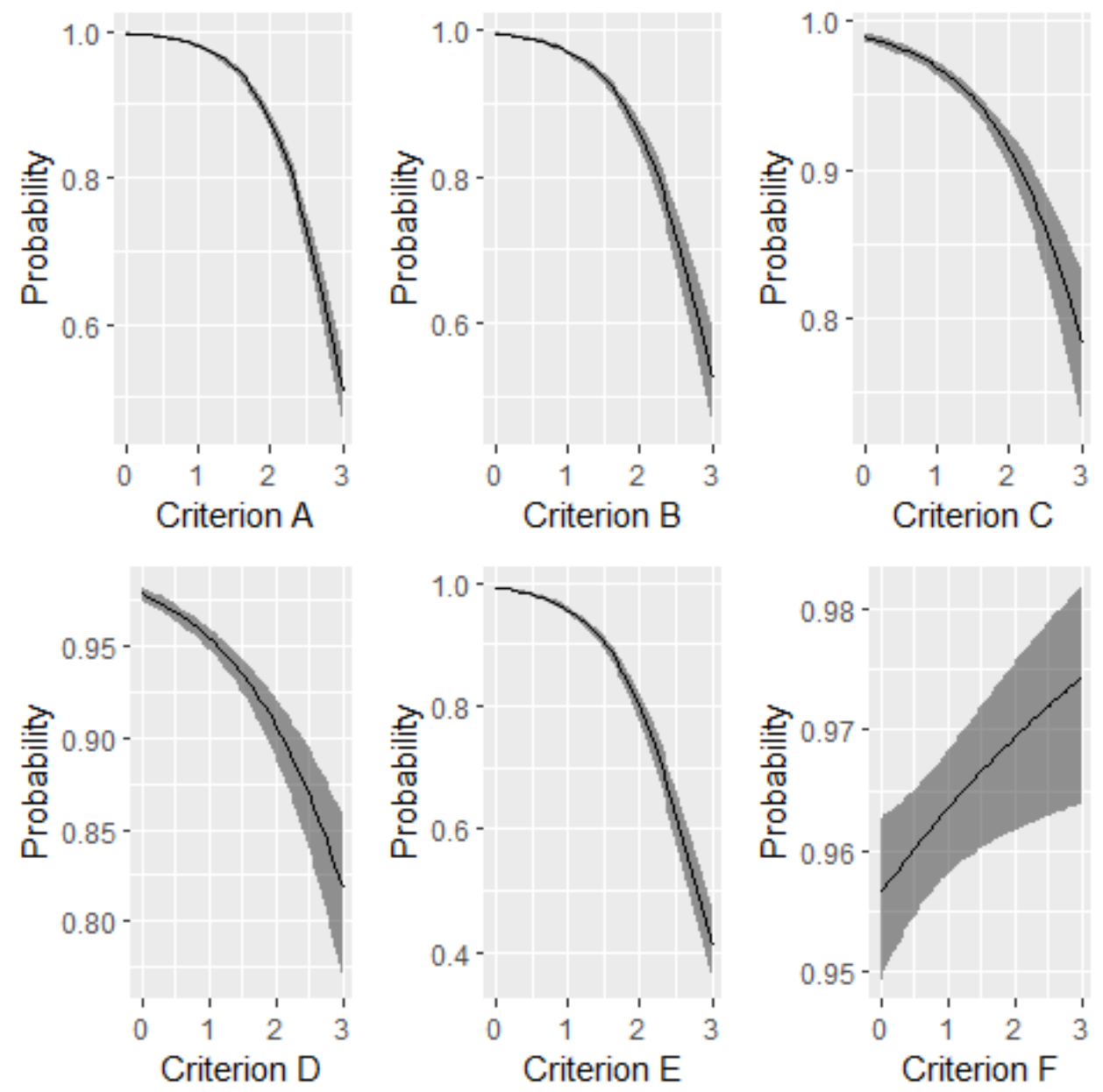

Figure 1. Dependence of the probability of using information judgments on the application of criteria A-F

The graphs in Figure 1 reflect the tendency of a sharp drop in the probability of using the information judgments in the case of using a higher intensity of epistemic criteria, which is characteristic of general deliberative and cognitive deliberative judgments. For example, in the case of criterion A, the informational relevance of the topic for communication participants using the information judgments is neutral. If the topic acquires a special personal meaning for the sides of the interaction, then the intensity of deliberation increases, and we move from an information judgment to a general deliberative or cognitive deliberative judgment, which can be seen in Figure 1 in relation to criterion A. Similarly, it is possible to trace the relationship between the probability of using information judgments and criteria B, C, D, E.

Thus, this platform favors the epistemic abilities of communication participants related to informational relevance (criterion A), task demands (criterion B), and directional motivation (criterion $\mathrm{E}$ ). These abilities are more significant for the formation of information judgments than the engagement of cognitive resources (criterion C) and non-directional motivation (criterion D). The latter, apparently obeying the logic of the platform, are discreetly used by participants. On the platform, there is a direct relationship between the epistemic capacity responsible for epistemic authority (criterion F) and the dependent variable, which indicates the importance of confirming the response by a representative of the authority through recourse to expert knowledge in the informational type of communication. The formation of platforms suitable for deliberative communication should help to activate the relevant criteria of everyday epistemics that influence the formation of general deliberative and cognitive deliberative judgments. 


\section{CONCLUSION}

Analysis of judgments on the platform 'Our St. Petersburg' allows us to assert that we have a platform dominated by the information type of communication, built on the behavioral principle of 'question-answer' and does not involve extensive deliberations. A descriptive analysis of variations within the information judgments shows a slight decrease in the mean values in relation to criterion E 'Directional motivation' and criterion F 'Epistemic authority', which confirms the limited ability of citizens to develop public communication and influence decisions within this platform. Analysis using logistic regression shows the presence of a direct connection between the criterion of 'Epistemic authority' and the probability of using information judgments in the process of communication on the platform 'Our St. Petersburg'. We acknowledge that future research should include analysis of these types of judgements on other types of platforms mentioned above in order to develop deliberative type of communication.

\section{ACKNOWLEDGEMENT}

This work was supported with a grant from the Russian Foundation for Basic Research (grant \#20-011-31361 'Outsourcing of Political Judgment: A Critical Analysis of the Information Paradigm of Network Public Communication').

\section{REFERENCES}

Akopov, G.L., 2015. The Internet and Politics. Modernization of the Political System on the Basis of Innovative Political Internet Communications. Moscow: ConRus;

Bossetta, M., 2018. The Digital Architectures of Social Media: Comparing Political Campaigning on Facebook, Twitter, Instagram, and Snapchat in the 2016 U.S. Election. In Journalism \& Mass Communication Quarterly, Vol. 95, No. 2, pp. 471-496;

Bykov I.A., 2013. Network Political Communication: Theory, Practice and Research Methods: Monograph. St. Petersburg: Publishing house SPGUTD;

Computational Propaganda: Political Parties, Politicians, and Political Manipulation on Social Media, 2019. / Ed. by S. Woolley and P. Howard. Oxford: Oxford University Press;

Fetzer, J., 2004. Disinformation: The use of false information. In Minds and Machines, Vol. 14, No. 2, pp. 231-240;

Howard, P., 2010. The Digital Origins of Dictatorship and Democracy Information Technology and Political Islam. Oxford: Oxford University Press;

Kreiss, D. and McGregor, S., 2018. Technology Firms Shape Political Communication: The Work of Microsoft, Facebook, Twitter, and Google With Campaigns During the 2016 U.S. Presidential Cycle. In Political Communication, Vol. 35, No. 2, pp. 155-177;

Kruglanski, A. W., Pierro, A., Mannetti, L., Erb, H., and Young Chun, W., 2007. On The Parameters of Human Judgment. In Advances in Experimental Social Psychology, Vol. 39, pp. 255-303;

Kruglanski, A., 1999. Motivation, Cognition and Realty: Three Memos for the Next Generation of Research. In Psychological Inquiry, Vol. 10, No. 1, pp. 53-58. Available at https://doi.org/10.1207/s15327965pli1001_8;

Kruglanski, A., Orehek, E., Dechesne, M. and Pierro, A., 2010. Lay Epistemic Theory: The Motivational, Cognitive and Social Aspects of Knowledge Formation. In Social and Personality Psychology Compass, Vol. 10, No. 4, pp. 939-950. Available at https://doi.org/10.1111/j.1751-9004.2010.00308.x;

Lukito, J., 2020. Coordinating a Multi-Platform Disinformation Campaign: Internet Research Agency Activity on Three U.S. Social Media Platforms, 2015 to 2017. In Political Communication, Vol. 37, No. 2, pp. 238-255;

Morozov, E., 2011. The Net Delusion: The Dark Side of Internet Freedom. New York: Public Affairs.

Volodenkov, S.V., 2018. Internet Communications in the Global Space of Modern Political Governance. Moscow: Prospect; 